\title{
Group Work Satisfaction At The University: An Innovative Experience In The New Higher Education Degrees
}

Raúl del Pozo-Rubio, University of Castilla-La Mancha, Spain Pablo Ruiz-Palomino, University of Castilla-La Mancha, Spain

Ricardo Martínez-Cañas, University of Castilla-La Mancha, Spain

\begin{abstract}
A methodology based on group work to facilitate the assimilation of the concepts and competences to be acquired by university students is presented as part of the teaching activities in second and third courses in the Business and Management Administration Degree at University of Castilla-La Mancha (UCLM). This methodology allows that students benefit from synergies between group members and complete the training received with one system that permits, in a better way, the achievement of a series of important generic and specific competences.
\end{abstract}

The present article is aimed at assessing student satisfaction after the completion of the group work activity in terms of motivation and involvement. The authors conclude that the degree of satisfaction is acceptable and good and that the activity per se is perceived as having a close relationship to the themes of the corresponding subject. An important collaboration between group members is observed, although there are students who shirk their responsibilities fully.

The study concludes that group work is a good teaching and learning tool that facilitates the acquisition of a series of important specific and generic competencies to pass the subject and at a low investment of study time.

Keywords: Group Work; Satisfaction; Innovative Experience; Student; University

\section{INTRODUCTION}<smiles>c1ccccc1</smiles>

panish universities have been forced to change their philosophy of work due to incorporation into the European Higher Education Area (EHEA), which highlights the importance of teamwork from two aspects: first, as a methodology that encourages the student to perform active and participatory work processes and secondly, because teamwork is currently one of the most valued skills in professional environments (Guitert, Romeu, \& Perez-Mateo, 2007). By extension, the assessment methodology - the tool used to asses acquisition, understanding and application of knowledge to be obtained from the subject - is forced to adapt to the evaluation of the new role acquired by the student. So we go from assessing knowledge to assessing a range of skills which students must prove they have acquired and mastered (Huber, 2008; Martinez-Martín \& Viader-Junyent, 2008; Palomares, 2010).

The establishment, definition and distribution of competences to be achieved by the student, by passing each subject individually and collectively and finishing the degree completely, are collected in a special record in each degree in every university. These competencies can be generic or specific. This report is subject to review by the National Agency for Quality Assessment and Accreditation (ANECA in Spanish), whose approval is sine qua non for the supply and teaching of the corresponding degree. 
In this new conception of Higher Education, students are overwhelmed with the assumption of new responsibilities, whereas they lack enough maturity during college years which allows them to be autonomous and self-sufficient. There is also a significant lack of knowing how when it comes to asking for help and knowing what it is that they actually need (del Rincón-Igea, 2000). The student should not be considered as a potential graduate who needs to be trained exclusively in theoretical terms. Rather, the complexity of the shape of the current economic environment, social order and the prevailing market system, which are harshly competitive, suggests that students need a broader, more complete and autonomous learning process through new methodologies and to work in groups (Ortega-Ortega \& Molina-Moreno, 2011). They actually need a learning process allowing them to complete their extracurricular training oriented to new patterns of labour demand and to see themselves with sufficient resources and skills to survive in the labour market (del Pozo-Rubio, Ruiz-Palomino, \& Martínez-Cañas, 2014).

The aim of this paper is to present a new methodology to facilitate the assimilation of the concepts pertaining to two different subjects of knowledge, such as Investment and Business Financing and Operations Management, whose students belong to the second and third year of the Business Administration and Management Degree. Whereas their training is complemented with master lectures and other teaching and learning activities, group work is one important activity in order to assess the achievement of both generic and specific competences established for each subject. This research is focused on the evaluation of student satisfaction after the completion of group work in order to determine their degree of motivation, commitment and involvement with this learning methodology.

\section{MATERIAL AND METHODS}

Group work activity evaluated here is developed during the second semester of Investment and Business Financing - a year-long course consisting of nine credits during the second year of the degree - and Operations Management - a semester course of six credits in the second semester of the third year, both in the Business Administration and Management Degree offered and taught at the University of Castilla-La Mancha in the campus of Cuenca. While the first subject falls within Module 7 of this degree's curriculum, whose area of expertise is Finance, the second subject corresponds to Module 5 of the curriculum - Business Organization.

Both are cases of courses which have a large, diverse and ambitious syllabus with considerable difficulty, especially for a second-year course of Finance and the third one of Business Organization. In fact, since the introduction of this degree at the University of Castilla-La Mancha, it has been observed in both subjects that there is extraordinary difficulty added in the understanding and acquisition of concepts, knowledge and given axioms. This may have been caused as a consequence of the redesign of the curriculum, which translates blocks of knowledge from the fourth and fifth-year courses of the degree to the second and third years of the new Bachelor system, respectively. Also, three main aspects should be pointed out: 1) training and knowledge maturity in second and third-year courses is not similar to the previous, 2) in the new Bachelor degree, there are no subjects of econometric nature or advanced statistics until the third year, and 3) the second year of the new degree presents four annual subjects, contributing to the appropriate increase of the level of difficulty.

In this agenda of Business Organization and Finance areas, students are proposed the implementation of a work group having a similar duration to that of the second term, coinciding with the completion of it. The objective of his learning activity is to put into practice the theoretical knowledge acquired in the subjects. Work will be performed in groups of four to five people as a maximum.

\section{RESULTS}

Of the students who completed the questionnaire (109 people), 39.45\% are male (43) and $60.55 \%$ female (66); 68 people live in the city of Cuenca $(62.39 \%)$, while $34(31.19 \%)$ do so in the province and seven reside outside the province $(6.42 \%)$.

Regarding the perception of teamwork design $2.75 \%$ (3) give low marks to the degree of relationship between group work and theme of the subject, 33.94\% (37) value this relationship as average, and $63.30 \%$ (69) give it high marks; $90.83 \%$ (99) believe that the criteria for assessing group work before starting it are clearly defined, 
while $9.17 \%$ (10) do not think so; and $77.06 \%$ (84) believe that the completion of group work will help them pass the subject, while $22.94 \%$ do not think so (25).

They are also asked about the degree and extent to which the performance of group work will allow them to develop their skills in both their future careers and in their personal life. In the first case, 77.98\% (85) answered yes, while $22.02 \%$ (24) do not believe that this can serve them for such support. In the second case, relating to personal skills, $86.24 \%$ (94) answered positively, while $13.76 \%$ (15) gave a negative answer.

Upon completion of the work in terms of time spent, when asked about the estimated time they employed completing it, 15 students (13.76\%) estimated a total of less than 10 hours, $63(57.80 \%)$ estimated between 10 and 20 hours, $26(23.85 \%)$ placed it between 20 and 30 hours, and $24.88 \%$ (31) estimated more than 30 hours invested. Of the total surveyed, $75.23 \%$ (82) believe that the time spent on group work is compensated with the highest rating that can be obtained by performing it, while $24.77 \%$ (27) do not consider that the time is offset by the percentage of the final grade. Complementing this time, they were asked about tutoring assistance to resolve any doubts arising in the resolution process of the work. In this sense, 37 students (33.94\%) say they have attended tutorials, 28 (25.69\%) have attended tutorials once or twice, and $44(40.36 \%)$ have attended three or more times.

Regarding the collaboration and contribution of members of the group, 68.63\% (35) stated that the degree of participation of all members of their group has been even, while $31.37 \%$ (16) did not feel the same way in terms of participation. Completing this information, 5.88\% (3) consider that they have worked less than their peers, $84.31 \%$ (43) think they have participated in developing the work similarly to their peers, while the remaining $9.80 \%$ believe that their participation in the study was higher than that shown by their peers. Finally, 25 students (22.94\%) consider that a classmate has remained totally absent during the performance of group work, while 84 people $(77.06 \%)$ answered negatively on partners being absent while doing the work.

Based on the above, nine students (8.26\%) report having a low level of satisfaction, 56 (51.38\%) show a medium level of satisfaction, and $44(40.37 \%)$ show a high degree of satisfaction (total analysis categories: none, low, medium and high) with the completion of group work with the current design.

As a further step to this report, a logistic regression model is estimated to locate the variables that affect the level of student satisfaction when doing group work. The results of this estimation are shown in Table I.

Table I: Ordered Logistic Regression Model Of Variables Associated With Satisfaction Level In Student Group Work

\begin{tabular}{|c|c|c|c|c|c|c|}
\hline & \multirow[b]{2}{*}{$\beta$ Coefficient } & \multirow[b]{2}{*}{$\mathbf{t}$} & \multirow[b]{2}{*}{ Odds Ratio } & \multicolumn{3}{|c|}{ Margins Effects Satisfaction Level } \\
\hline & & & & Low & Medium & High \\
\hline Course & -1.296 & $-2.30^{\mathrm{b}}$ & 0.274 & $0.086^{\mathrm{b}}$ & $0,137^{\mathrm{b}}$ & $-0.223^{b}$ \\
\hline Work/Subject Themes relatedness & 1.749 & $2.87^{\mathrm{a}}$ & 5.750 & $-0.116^{\mathrm{b}}$ & $-0.184^{\mathrm{a}}$ & $0.300^{\mathrm{a}}$ \\
\hline $\begin{array}{l}\text { Degree of equitable } \\
\text { participation of members }\end{array}$ & -1.113 & $-2.17^{\mathrm{b}}$ & 0.328 & $0.074^{\mathrm{b}}$ & $0.117^{\mathrm{b}}$ & $-0.191^{b}$ \\
\hline Constant 1 & -2.867 & & & & & \\
\hline Constant 2 & 0.941 & & & & & \\
\hline Chi-2 & & & & & & \\
\hline $\mathrm{R}^{2}$-Adjust $\quad 20.25 \%$ & & & & & & \\
\hline
\end{tabular}

As shown in Table I, all the variables gain statistically significant parameters which need be interpreted on the basis of the figures observed in the "high" Margins Effects Satisfaction Level column. According to results shown in this area of Table I, students in the third course are $22.3 \%$ more satisfied with the group work activity than students in the second course. Also, those students who perceive a strong connection between the work group activity and the subject themes seem to show a higher level of satisfaction with the former activity. Specifically, there is a $30 \%$ probability that these students' satisfaction level with the group work activity is higher. Finally, students who perceive that there is an inequitable degree of participation among the group members, compared with those students who perceive an equitable degree of participation, are $19.1 \%$ less satisfied with this work group activity. 
In a subsequent analysis, the question is whether the model presented in Table I improves its overall adjustment when using weighting variables in the econometric analysis. Results of these new estimates are shown in Table II. As noted, when weighted by gender and place of residence, the new models remain statistically significant globally, increasing a little their measure of goodness of fit " $\mathrm{R}^{2}$-Adjust", and the parameters associated with individual variables continue to result statistically significant.

Table II: Logistic Regression Models Alternatives To Model 1 By Using Weighting Variables

\begin{tabular}{lccc} 
& Weighting Variable & Chi-2 & R $^{2}$-Adjust \\
\hline Model 1 & - & $40.35^{\mathrm{a}}$ & $20.25 \%$ \\
\hline Model 2 & Gender & $41.62^{\mathrm{a}}$ & $21.30 \%$ \\
\hline Model 3 & Place of Residence & $44.86^{\mathrm{a}}$ & $21.71 \%$ \\
\hline${ }^{\mathrm{a}}$ Indicates significance at $1 \% ;{ }^{\mathrm{b}}$ Indicates significance at 5\%; ${ }^{\mathrm{c}}$ Indicates significance at $10 \%$ &
\end{tabular}

\section{CONCLUSIONS}

From the satisfaction survey conducted in this study, it can be concluded that the degree of satisfaction with the group work activity is considerably acceptable or good, although there is margin and room for improvement. The strong relationship between learning content involved in the group work activity and the syllabus of the course is considered a positive and notorious point, and the time required and/or assigned to complete the activity does not confer a significant problem. It should be noted that group work is appreciated when it relates to employment and personal skills, especially the latter, which may be developed in the near future in the labour market. In terms of group collaboration, four out of five students responded that there have been no problems in conducting collaborative work: there have been no transfers of workload between them, nor any shirking of responsibilities. However, one-fifth of the students responded affirmatively to the existence of these issues. Finally, the variables 1) course, 2) student's perceived relationship between the content of the course and the work design, and 3) level of inequitable participation of all group members completing it become statistically significant variables that explain the level of student satisfaction in performing such learning activity.

The use of this group work activity allows students to achieve much more than what is attained by exclusive academic training. Orderly, they do show how it's done, know how to do it, and know (Miller, 1990; Tolentino, 2012) the following skills, both generic and specific, pertaining to the knowledge areas of Finance (Investment and Business Financing) and Business Organization (Investment and Business Financing). Generic ones which are achieved include:

G1: Possessing skills for lifelong learning, self-directed and autonomous, allowing them to develop learning skills needed to undertake further study with a high degree of autonomy

G2: Understanding the ethical responsibility and professional deontology for economists - knowing and applying the law, recognizing human rights and considering gender issues

G4: Using ICT appropriately, applying them to the appropriate business department specific programs for such business fields

G5: Ability to work in a team leading, directing, planning and supervising multidisciplinary and multicultural teams in the national and international business environment and their departments so that beneficial synergies for the company are achieved

Some other specific competencies that are also achieved include:

S3: Establishing the planning and organization for any labor task in order to facilitate business decision making

S5: Developing the ability to transform a company and analyze it in business opportunities based on any information records about the situation and possible developments of the company

S7: Understanding the economic environment as a result and application of theoretical or formal representations of how the economy works. For this, they will be able to understand and use common manuals and articles and, in general, state of the art bibliography in the main subject of the curriculum.

S11: Understanding the operation and consequences of different economic systems

S13: Capacity to perform representative logical models of business reality 
In conclusion, the activity described in this document is intended to provide students with specific resources and capabilities that allow them to connect theory with practice and empirical evidence. Such activity also fosters in them to use real information and tools to meet the needs arising from work, get involved in group tasks and what that entails, perform extensive work following the guidelines of a full and intense agenda, and pass a course with a considerable level of demand and difficulty.

\section{AUTHOR INFORMATION}

Raúl del Pozo-Rubio is Assistant Professor of Finance at University of Castilla-La Mancha, Spain (UCLM). He is a $\mathrm{Ph} . \mathrm{D}$ in Finance and his current research interests are focused on long-term care costs and financing, as well as on

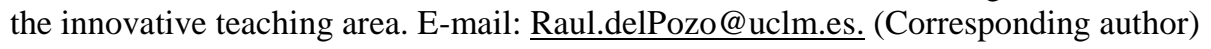

Pablo Ruiz-Palomino is Associate Professor of Business Administration at UCLM. He is a Ph.D. in Business Administration and his research interests are focused on business ethics and social capital. His research experience is also oriented toward the innovative teaching area. E-mail: Pablo.Ruiz@uclm.es.

Ricardo Martinez-Cañas is an Associate Professor of Business Administration at UCLM. He is a Ph.D. in Business Administration and his main research interests are business ethics and social capital. Education is also one of his important research areas of interest. E-mail: Ricardo.Martinez@uclm.es.

\section{REFERENCES}

1. Del Rincón-Igea, B. (2000). Tutorías personalizadas en la universidad. Cuenca: Servicio de Publicaciones de la Universidad de Castilla-La Mancha, Universidad de Castilla-La Mancha.

2. Del Pozo-Rubio, R., Ruiz-Palomino, P., \& Martínez-Cañas, R. (2014). Educational innovation and personalized tutoring in higher education: A personal and professional guidance. Journal of International Education Research, 10: 89-92.

3. Guitert, M., Romeu, T., \& Pérez-Mateo, M. (2007). Competencias TIC y trabajo en equipo en entornos virtuales. Revista de Universidad y Sociedad del Conocimiento, 4 (1): 1-12.

4. Huber, G. L. (2008). Active learning and methods of teaching. Revista de Educación, Número Extraordinario, 59-81.

5. Martínez-Martín, M. \& Viader-Junyent, M. (2008). Learning and teaching in a context of change in the university. The promotion of Teaching Team. Revista de Educación, Número Extraordinario, 213-234.

6. Ortega-Ortega, M. \& Molina-Moreno, V. (2011). Estrategia metodológica para el aprendizaje cooperativo dentro del nuevo EEES: "Juego de retroalimentación”. II Jornadas sobre Innovación Docente y Adaptación al EEES en las Titulaciones Técnicas (pp. 313-316), Granada: Editorial Godel Impresores Digitales S.L.

7. Palomares-Ruiz, A. (2010). The educational model at university and the use of new methodologies for teaching, learning and assessment. Revista de Educación, 355: 591-604.

8. Miller, G. E. (1990). The Assessment Of Clinical Skills/Competence/Performance. Academic Medicine, 65 (9): 63-67.

9. Tolentino, M. (2012). Adaptación al Espacio Europeo de Educación Superior de las asignaturas de Finanzas en la Facultad de Derecho y Ciencias Sociales de Ciudad Real: Relación entre actividades formativas y adquisición de competencias. In Farinós-Viñas, J. E. \& Furió-Ortega, M. D. (Eds). II Jornada de Intercambio de Experiencias de Innovación Educativa en Finanzas, Valencia, Universitat de Valencia: Ediciones Reproexpress S. L. 
NOTES 